\title{
Survey on total fire safety in residential care homes for elderly persons in Hong Kong
}

\author{
G. C. H. Lui \& L. Y. C. Tong \\ Department of Building Services Engineering, \\ The Hong Kong Polytechnic University, China
}

\begin{abstract}
With a demographic shift in the ageing population in Hong Kong, more elderly people, in particular those with cognitive impairment, physical disabilities, chronic illness, mild mental disorder and those who suffer from frailty, are unable to take care of themselves. Many of the elders become more dependent and require long-term care. Thus, there is a rising demand on home care and effective supervision for the elderly, such as the Residential Care Home for the Elderly (RCHE). However, it is obvious that if fire occurs in these buildings, the elderly with poor mobility, in wheelchairs or those that are bedridden are in great danger and in need of sufficient assistance from able-bodied people. Public concern on the fire safety aspects of RCHEs is advancing after several recent fires. Sufficient provisions and staff assistance should be available in the case of fires in RCHEs.

In order to understand the current situations of the fire safety provisions in RCHEs, a questionnaire survey was conducted at 43 RCHEs all around Hong Kong from November 2007 to January 2008. In this paper, the survey results and corresponding analysis are presented to reveal the local situation. Five parts, building nature and background information, active fire services installations (FSIs), passive building design (PBD), fire risk factors and fire safety management (FSM), are discussed. The overview on the survey results is drawn to identify the major inadequacies in the fire safety aspects of the RCHEs. Total safety in RCHEs can only be provided with good software for FSM in governing the hardware of FSIs and PBD. Relevant statutory regulations should be imposed to deal with the deficiency and improve the situation in RCHEs. The survey data is further useful to simulate the probable fire environment and elders' behavior in RCHEs using zone models and evacuation models, respectively, in future studies.
\end{abstract}

Keywords: survey, total fire safety, residential care homes, elderly homes. 


\section{Introduction}

With a demographic shift in the ageing population in Hong Kong [1, 2], more elderly, in particular those with cognitive impairment, physical disabilities, chronic illness and mild mental disorders, are unable to take care of themselves. Many elders become more dependent and rising demand on long-term residential care, effective supervision and guidance for the elderly, such as the Residential Care Home for the Elderly Persons (RCHE) [3], have resulted.

It is obvious that if fire occurs in these RCHEs, elderly with poor mobility are in great danger. Some can still evacuate by themselves but they may need to walk carefully and may pose falling risks. Others, particularly those that are bedridden, are in greater need of assistance from able-bodied people. Subsequent to recent fires in RCHEs and in old composite buildings with RCHEs located in them, public concern is advancing for the safety of the elderly and fire safety provisions in RCHEs. Sufficient fire safety aspects and staff assistance should be available in case of fire in RCHEs.

From previous research studies, the codes governing the fire safety aspects of RCHEs in Hong Kong were reviewed [4]. In this paper, the survey methodology, results and corresponding analysis are presented to reveal the real situation of local RCHEs. Investigations on building nature and background information, passive building design (PBD), active fire services installations (FSI), fire risk factors and fire safety management (FSM) were carried out. The major inadequacies in the fire safety aspects of the RCHEs were identified from the survey results. It is noted that good FSM software is necessary to govern the FSI hardware and PBD in order to ensure total fire safety in RCHEs. Therefore, it is suggested to impose related statutory regulations to improve the situation.

\section{Questionnaire survey}

The questionnaires on reviewing the current situations of the fire safety aspects of the RCHEs were firstly sent to, and completed by, home managers in 18 districts of Hong Kong. Interviews and direct meetings were further conducted to ensure all questions were correctly interpreted and responded to. This helped to minimize any inconsistencies in the returned data and increase the accuracy.

In the survey, 103 questionnaires were firstly distributed to local licensed RCHEs from November 2007 to January 2008. RCHEs with different levels of care and attention were considered. Among the questionnaires sent, 45 questionnaires were returned, giving a response percentage of $44 \%$. After thorough checking, 43 of the returned questionnaires were acceptable for further analysis. In order to ensure a more precise justification of the survey data, another survey was conducted from late January to February 2008. Consequently, the 43 questionnaires with good responses were anticipated to be good indicators, which revealed the real situation of the fire safety aspects in local RCHEs. 


\section{Building nature and background information}

Questions set in the survey include the type, foundation year, location, floors occupied, functional use of building where the RCHE is located, floor area, type of organization that runs the RCHE, etc. The survey data was analyzed under these aspects, which helped to look into the current operation situation and provisions in local RCHEs.

\subsection{Concern of foundation years of RCHEs}

The foundation time of the RCHEs is one of the essential considerations in the survey. There were critical conversions in the regulatory control to the fire safety aspects and the management in the four periods: before 1972, from 1972 to 1987 , 1987 to 1995 and after 1995. For those RCHEs founded before 1972, there was a deficiency in FSI in those old buildings as only fire hydrant and hose reel (FH/HR) systems were installed. Both the Hong Kong Government and the home managers of RCHEs were still neglectful of the fire safety provisions during this period. Although there were strategies of home managers paying more attention to fire safety provisions in the RCHEs, insufficient guidelines and regulations were provided for them to monitor the feasibility of installing FSI.

The situation changed after 1989 after a serious fire bombing accident occurred. More major fire extinguishing installations, like automatic sprinkler systems were adopted and efficient fire control systems were increasingly emphasized. Moreover, strict legislation had been imposed to govern the FSI inside the RCHEs and effective licensing system had been implemented to monitor the suitability of this aspect. The transition period for all the RCHEs to comply with all the requirements related to the FSI lasted till 1995. This means that all the RCHEs have to meet all the FSI requirements after 1995.

From the survey, it was found that $72 \%$ of the RCHEs were established after 1995, 21\% were established between 1987 and 1995 and only 7\% was established between 1972 and 1987, as shown in Figure 1. After the comprehensive survey on the conditions of all the FSI, all the RCHEs have met all the licensing requirements in the relevant codes [5].

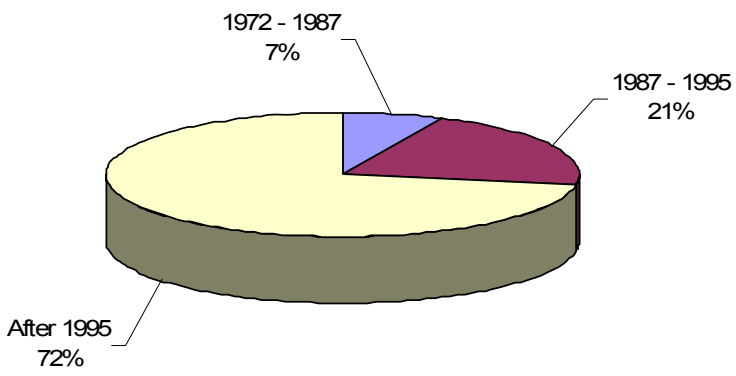

Figure 1: $\quad$ Year of foundation of RCHEs. 


\subsection{Concern of the floors occupied by RCHEs}

From the survey results, it is found that all the RCHEs were mainly located on lower floors, irrespective of the functional uses of the buildings. Sixty-seven percent of the RCHEs occupy only G/F or floors with G/F included in buildings. On the other hand, the highest floor occupied by an RCHE is 7/F. This trend can obviously facilitate the evacuation progress of the residents inside the RCHEs and the means of access for firefighters during the outbreak of fires. As the occupants' lifts should not be used in case of fire, the residents on lower floors in the buildings were expected to evacuate by staircases. It is not feasible for the weak/elderly with low mobility to evacuate from higher floors in buildings. The evacuation time would be prolonged. Suffocation and low visibility of the elders may also occur. Consequently, the locations of the RCHEs inside the buildings are one of the major factors of means of escape and the PBD of the fire safety aspects.

It is also noted that RCHEs occupy different numbers of floors, which vary from one to seven floors in buildings. The distribution is shown in Figure 2.

It is found that the average total floor area occupied by the RCHEs was 1,478 $\mathrm{m}^{2}$; the largest floor area being $7,909 \mathrm{~m}^{2}$ over six floors, whilst the smallest floor area of $128 \mathrm{~m}^{2}$ occupying the ground floor only. The distribution of the total floor areas occupied by RCHEs is shown in Figure 3. Sixty-five percent of RCHE establishments were of rectangular shape and that of irregular shape accounted for the smaller proportion of only $35 \%$.

\subsection{Concern of functional use of buildings that accommodate RCHEs}

It was found that $58 \%$ of the RCHEs are located inside residential buildings, including public housing estates. About $33 \%$ are inside separate buildings, which mean they are independent buildings with the whole buildings being operated under the RCHEs or under the same organization (such as those in communal buildings). Other occupants will not affect evacuation from these independent buildings. Five percent of RCHEs were located in composite buildings, with

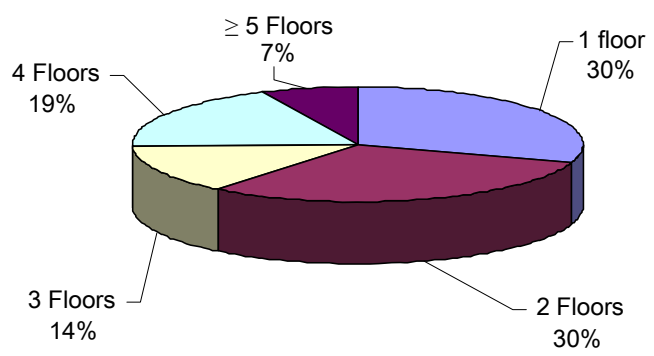

Figure 2: Number of floors occupied by RCHEs. 


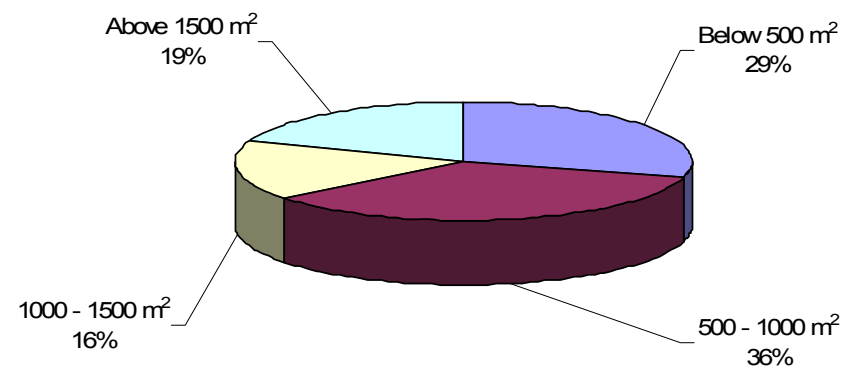

Figure 3: Total floor area occupied by RCHEs.

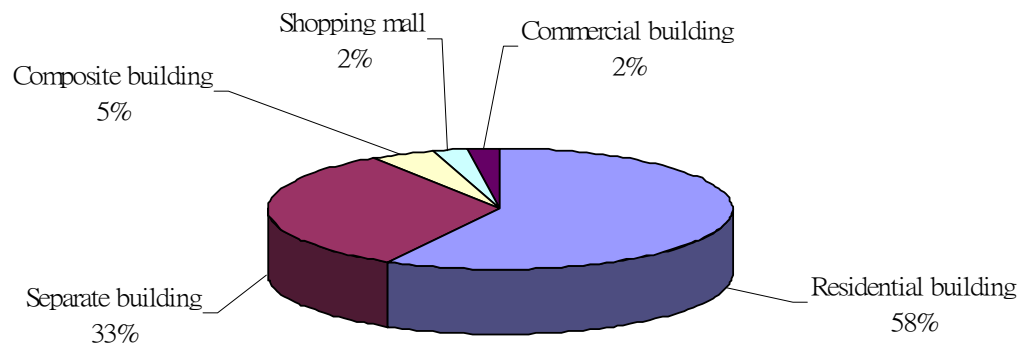

Figure 4: Functional use of buildings used for accommodating RCHEs.

combined residential accommodation and shopping malls. The high occupant loading from other parts of the buildings may affect the evacuation of the elders from the RCHEs. Such considerations should also be taken into account when planning the fire action plan and evacuation procedures in the RCHEs. The distribution of functional uses of buildings that RCHEs accommodate in is summarized in Figure 4.

\section{Fire services installations}

All the FSI, such as fire detection system, fire alarm system, fire extinguishers, fire blankets, FH/HR system, automatic sprinkler system, emergency bell system and smoke control (SC) system listed in the relevant requirements in the local codes [5] were surveyed in all RCHEs. Most FSI provided in the RCHEs satisfied the requirements as listed in local codes. However, it was observed that there were three surveyed RCHEs with floor areas more than $230 \mathrm{~m}^{2}$, which did not install the automatic sprinkler system and did not satisfy the regulations [5]. Moreover, none of the RCHEs has SC systems.

The quantities of some FSI, such as smoke/heat detectors, different kinds of fire extinguishers $\left(\mathrm{CO}_{2} /\right.$ Water type $)$, fire blankets, and emergency bells were also recorded in the RCHEs. Each smoke detector was found to cover $8.29 \mathrm{~m}^{2}$ to 25.3 $\mathrm{m}^{2}$ and this is within the requirement on the area coverage of $100 \mathrm{~m}^{2}$ per smoke 
detector. These data will further be useful for more comprehensive studies on these aspects specific to local RCHEs in the future. They are also crucial for the estimation of the density of the FSI to work out the most efficient functioning and maintenance of FSI for different types of RCHEs.

\section{Passive building design}

All the PBD requirements like minimum corridor width, number of staircases and exits, floor heights and any fire-resistant structures have been surveyed. Effective PBD can limit the spread of fire within the RCHEs and facilitate the evacuation of the residents. Arrangement of rooms inside the RCHEs was also surveyed to investigate their influence to the accessibility of evacuation routes.

It was observed that only $24 \%$ of the RCHEs had the minimum corridor width, which is $1.2 \mathrm{~m}$, while the percentages of other corridor widths are shown in Figure 5. The average corridor width of all the surveyed RCHEs is $1.13 \mathrm{~m}$. Sufficient space should be allowed for elders to maneuver their wheelchairs in the corridors. Ignorance in some RCHEs was contributed to by the noncompulsory licensing requirements [6] in the relevant local codes.

The maximum number of exits and staircases within the RCHEs surveyed were six and five respectively. Among all the RCHEs surveyed, there were two RCHEs with the minimum number of one staircase and two exits respectively. One of the RCHEs occupied four floors inside a residential building. It revealed that there was a deficient number of escape routes as there were many other residents besides those in the RCHEs. It was unfeasible for all residents to evacuate from the fire scene by using only one staircase. Furthermore, in the two RCHEs with the largest floor areas of $7,909 \mathrm{~m}^{2}$ the number of exits and staircases are four and three, respectively. It illustrated that the numbers of exits and staircases were independent of the floor area of the RCHEs. However, this is an essential issue in the consideration of the density of occupant load and the evacuation procedures.

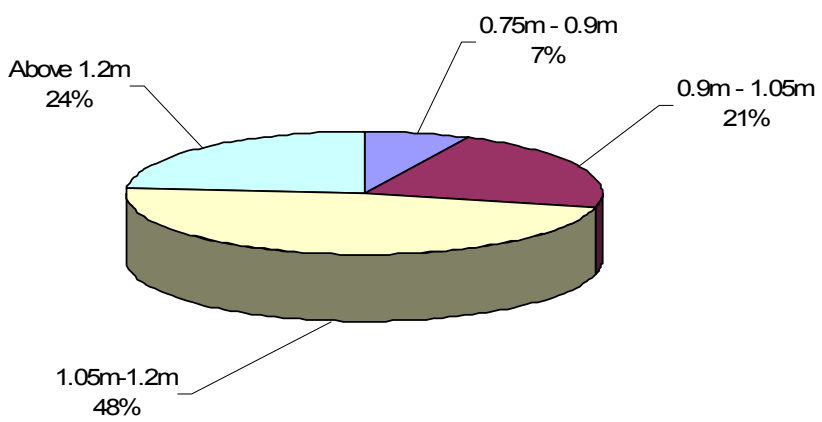

Figure 5: The minimum corridor width in RCHEs. 


\section{Fire risk factors}

Both occupancy load factor (OLF) and fire load density (FLD) are considered as fire risk factors. They are necessary to be considered as they will affect the numbers of evacuees from the floors in the premises and also the amount of heat released by burning all the combustibles inside the RCHEs.

\subsection{Occupancy load factor (OLF)}

OLF mainly concerns the maximum number of residents occupying the rooms/spaces within the RCHEs, at any instant and any probable situation. It is one of the essential considerations in the evacuation progress. Smaller OLF will allow more people to evacuate from the same floor simultaneously in case of fire.

It is observed that the smallest OLF among all the surveyed RCHEs was 4.4 $\mathrm{m}^{2} /$ resident in a home for the aged established between 1972 and 1987. It revealed that the longer established RCHEs still neglected the importance of OLF. On the other hand, the largest OLF was $30.5 \mathrm{~m}^{2} /$ resident of a nursery home with six floors in an independent building. It was because this RCHE was established within ten years and besides, higher levels of attention are required at nursing homes. The proposed OLF must be high in RCHEs to ensure more floor area in each floor is available for the evacuation of the elder residents, who have higher proportion of low mobility and immobility. It is observed that the OLF results were more satisfactory in the government-funded RCHEs, with the range of OLF within 11.6-30.4 $\mathrm{m}^{2} /$ resident.

The average OLF of all surveyed RCHEs was $10.96 \mathrm{~m}^{2} /$ resident and this fulfilled the OLF requirement set out in the Residential Care Homes (Elderly Persons) Ordinance [7]. However, this result cannot meet the minimum OLF standard, i.e. $11.1 \mathrm{~m}^{2} /$ resident in the Life Safety Code [8]. There is still room for improvement for better OLF provided in RCHEs in Hong Kong, especially for the non-government funded RCHEs and those established for more than 15 years.

\subsection{Fire load density (FLD)}

Fire load (FL) is one of the essential parameters considered in the potential severity of compartment fires could occur inside the RCHEs. FL inside the compartments in RCHEs is divided into fixed and movable FL. Fixed FL are combustible items that are unlikely to be changed or moved within the compartment area, such as backing of walls, ceiling, timber floors, full height partitions and the furnishing materials that enclose the space etc. Movable FL is the combustible materials that are put into the compartments after completing the construction and furnishing of walls, such as residents' beds, bedside cupboards, wardrobes, carpets, chairs, pillows, mattress etc.

FL is "the theoretical amount of heat that may be released during the burning of combustibles in the building under fire conditions" [5]. As FL depends on the size of RCHEs, larger RCHEs should contain more combustibles than the 
smaller ones. Therefore, the total FL alone does not enable a fair comparison to be made.

Instead, fire load density (FLD) is used for a unified comparison. It can be expressed as $\mathrm{J} / \mathrm{m}^{2}$ or $\mathrm{MJ} / \mathrm{m}^{2}$ or in terms of equivalent mass of wood $(\mathrm{kg}$ $\operatorname{mood} / \mathrm{m}^{2}$ ) by dividing the value in $\mathrm{MJ} / \mathrm{m}^{2}$ by the calorific value of wood (18.6 $\mathrm{MJ} / \mathrm{kg}$ ). In a compartment of $\mathrm{N}$ combustible items, FLD (in $\mathrm{MJ} / \mathrm{kg}$ ) can be calculated by dividing the product of the mass of the $i^{\text {th }}$ item $M_{i}$ (in $\mathrm{kg}$ ) and its calorific value $C_{i}$ (in $\mathrm{MJ} / \mathrm{kg}$ ) by the floor area $\mathrm{A}_{\mathrm{f}}\left(\mathrm{in}^{2}\right)$ as in eqn (1):

$$
F L D=\frac{\sum_{i=1}^{N} M_{i} \times C_{i}}{A_{f}}
$$

where $M_{i}$ is the mass of the $i^{\text {th }}$ item of combustible material $(\mathrm{kg})$

$\mathrm{C}_{\mathrm{i}}$ is the calorific value of the $\mathrm{i}^{\text {th }}$ item $(\mathrm{MJ} / \mathrm{kg})$

$\mathrm{A}_{\mathrm{f}}$ is the corresponding floor area $\left(\mathrm{m}^{2}\right)$

The elders usually occupy shared rooms and some are in open plan RCHEs with bed spaces. The maximum numbers of bedrooms and bed spaces in RCHEs surveyed were 136 and 161 respectively. In the questionnaire, the furnishing of rooms (wallpaper, carpet, and curtain), the quantities of furniture (bedside cupboards, wardrobes, chairs, beds) and the sleeping appliances (mattress covers, bedspreads, blankets, quilt) in the bedrooms and bed spaces were surveyed. Most furniture is made of wood, plywood and aluminum plate, while the bedding is made of polyurethane foam and cotton fiber, etc.

As the facilities inside typical bedrooms or bed spaces in the same RCHE are all similar to each other, the estimated FL in each bedroom or bed space was proposed to be the same. In addition, beds, bedside cupboards and wardrobes of standardized sizes are used. After collecting all the necessary data such as the number of different furniture and combustibles such as beds, bedside cupboards, wardrobes and the sleeping necessities inside the RCHEs, the total movable FL was evaluated by multiplying the FL of each item with their corresponding quantities inside the RHCEs. FLD in each RCHE was further determined.

From the results, it is observed that the estimated FLD ranged between 596 $\mathrm{MJ} / \mathrm{m}^{2}-1127 \mathrm{MJ} / \mathrm{m}^{2}$, which did not exceed the limit of $1135 \mathrm{MJ} / \mathrm{m}^{2}$ as stated in the local codes [5]. Figure 6 shows the FLD ranges in the RCHEs surveyed. Moreover, it is found that the FLD in those RCHEs established within 19721987 and 1987-1995 was larger than those found in the RCHEs in recent years. This reveals that the situation improved after the Social Welfare Department (SWD) implemented the licensing scheme in 1989. Several requirements have also been imposed to the manufacturing materials of the mattress, upholstered furniture and the other related accessories used in the RCHEs.

\section{Fire safety management}

FSM is the most crucial consideration in maintaining a high quality of fire safety. It involves the implementation of fire safety policy for the protection of 


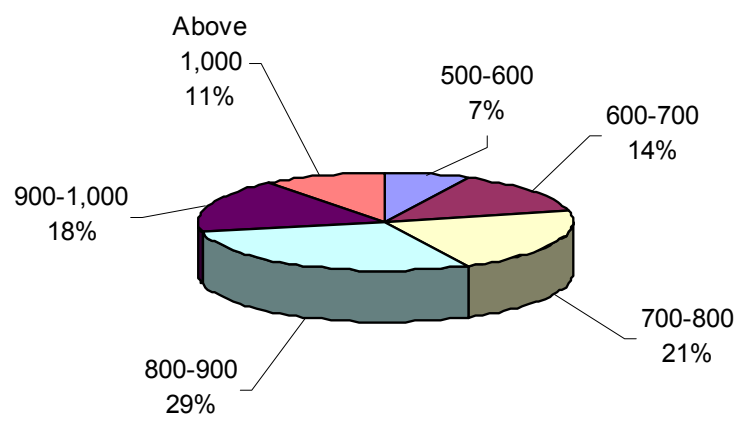

Figure 6: $\quad \mathrm{FLD}\left(\right.$ in $\left.\mathrm{MJ} / \mathrm{m}^{2}\right)$ in the surveyed RCHEs.

residents, staff and visitors, and the arrangements for planning, organizing and monitoring the fire safety measures in the RCHEs.

As the actions of staff are crucial to the safety of the elder residents, all staff (including temporary staff and agency staff) should be given appropriate information, training and possess skills to physically move or assist the residents to evacuate from the fire scene. Maintenance plan, staff training plan and fire action plans with risk reduction, FSI maintenance, correct actions to be taken in case of fire, skills to use fire-fighting equipments properly and high awareness of the importance of their safeguarding actions etc. are necessary [9].

Supervisory staff should have the managing skills on fire/ emergency action plan with correct evacuation procedures and fire drills should be carried out according to the regulations. They should also be given the details of the findings from the drills, maintenance and testing records so as to analyze the results and work out improvements on all fire safety aspects inside RCHEs.

\subsection{Late patrols and maintenance of FSI}

The provision of a late patrol every night and the annual inspection of FSI in RCHEs by registered FSI contractors are crucial requirements for fire risk reduction and the maintenance of FSI in RCHEs. It is found that all the RCHEs satisfied these two requirements as stated in the Residential Care Homes (Elderly persons) Ordinance [7].

In the ordinance, it also states that fire drills should be conducted once every six months, with proper records maintained. In the survey, it is observed that about $84 \%$ of RCHEs conducted fire drills every 6 months, 14\% conducted more frequent drills every 5 months or less. Therefore, most RCHEs emphasize the importance of fire drills and satisfied the ordinance. However, the remaining $2 \%$ of RCHEs conducted the fire drills only once every year. This should not be neglected and corresponding measures should be taken on them.

\subsection{Staff management}

From the survey results, about $67 \%$ of RCHEs were giving all staff basic information, training and instruction on the fire safety measures. The ratio of 
staff with basic training to total number of staff is $1: 1$ in this case. About $28 \%$ of RCHEs had the ratio of staff with basic training to total number of staff being $1: 2$ while the remaining $5 \%$ of RCHEs only had the ratio of 1:4. As this issue is the minimum requirement in the FSM aspects, it is anticipated that the proportion of staff with basic fire training should be increased.

Figure 7 shows the results of staff in RCHEs who have additional training on using evacuation aids and skills in physically assisting the residents to escape from the fire. Most residents in RCHEs with low mobility need staff to assist them to escape from the fire scene efficiently.

For the investigation on the number of staff implementing fire safety risk assessments and seeking improvements of FSI, it is found that most staff in RCHEs neglected the importance of this issue. Only 157 (15\%) out of 1,057 staff in all surveyed RCHEs had such training or works. It reflects that there was insufficient awareness, and that further improvement on FSI and fire risk factors existing in their working RCHEs should be considered. This is significant in minimizing fire risk and enhancing the integrity of evacuation progress.

Staff to resident ratio in RCHEs, as shown in Figure 8, is another important concern of FSM. During the evacuation from a fire scene, the number of staff inside the RCHEs was essential in aiding the elderly with low mobility to increase the efficiency of the evacuation progress. If the ratio of the number of staff to the elderly is too large, inadequate staff will be free to take an organization role and this will easily lead to serious disorder during the evacuation.

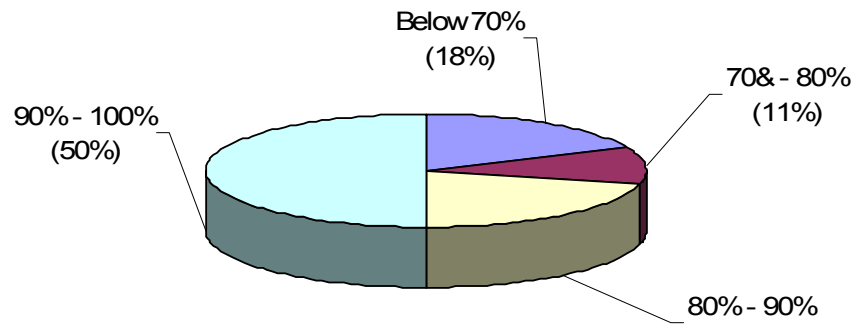

(21\%)

Figure 7: Percentage of staff in RCHEs who were familiar with evacuation aids and skills in assisting residents to evacuate during fire.

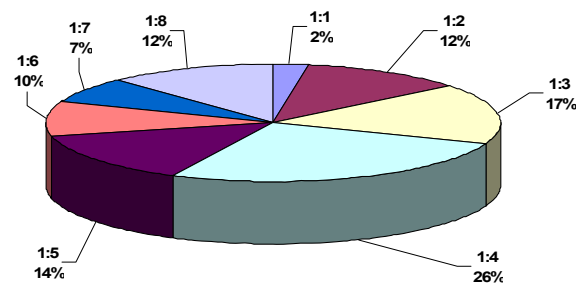

Figure 8: $\quad$ Staff to elderly ratio in RCHEs. 
It is observed that a large proportion (26\%) of RCHEs was providing 1:4 whereas only $14 \%$ could provide $1: 2$ and $1: 1$, which are the preferable ratios. By comparing to similar research done few years ago [10], there is a rising trend to provide only one staff member to serve five or more residents, while there are fewer RCHEs which provide one staff member to serve three elders or less. The case is aggravated for those RCHEs of smaller sizes. This may be due to lack of regulations governing the acceptable ratio of staff to residents, ignorance of the importance of FSM or the lack of awareness of staff in the assistance of elders during evacuation from fire.

\section{Conclusions}

The overall performance of FSI in local RCHEs was found to have improved in recent years due to stricter monitoring of the SWD and the abundant assistance of the Licensing Office of Residential Care Homes for the Elderly. However, further improvement should be implemented on PBD and FSM for RCHEs as statutory regulations are still lacking in these two aspects. There is no specified requirement on corridor width, which is an essential concern during evacuation. From the survey, the corridors in some RCHEs can just accommodate and allow one wheelchair to access. Further, on FSM, not only the staff-to-elderly ratio is large, but also there is also insufficient fire safety and evacuation training for staff.

The survey data obtained is useful in future improvement of the fire safety aspects and imposing relevant requirements. Besides, the data can further simulate probable fire environment and elder's behavior in RCHEs using zone models and evacuation models, respectively, which will be done in future studies.

\section{Acknowledgement}

This project with account code G-YF84 is supported and funded by PolyU.

\section{References}

[1] Services for the Older Persons in Hong Kong 2002. The Hong Kong Council of Social Service, Service Development (Elderly), HK, 2005.

[2] Hong Kong Population Projections 2007-2036. Census and Statistics Department, HK, 2007.

[3] Chan, Alfred C. M. Long term care for the elderly people in HK. Ageing policy and long term care in Hong Kong. Lingnan University, HK, 2001.

[4] Lui Gigi C. H. \& Tong Leo Y. C. Codes Review on Fire Safety Aspects in the Residential Care Homes for the Elderly Persons in Hong Kong. 26th International System Safety Conference, Vancouver, System Safety Society, Paper 1777, pp. 1-10, 2008. 
[5] Codes of Practice for Minimum Fire Service Installations and Equipment and Inspection, Testing and Maintenance of Installations and Equipment. Fire Services Department, HK, 2005.

[6] Code of Practice for the Provision of Means of Escape in Case of Fire. Buildings Department, HK, 1996.

[7] Residential Care Homes (Elderly Persons) Ordinance. Chapter 459, Laws of Hong Kong, HK, http://www.justice.gov.hk/Home.htm, 1997.

[8] Life Safety Code Handbook. National Fire Protection Association, 1997.

[9] Malhotra, H.L. Fire Safety in Buildings. Fire Research Station, Building Research Establishment, Department of the Environment, UK, 1987.

[10] Lui Gigi C. H. \& Lau K.Y. A survey on the fire safety aspects in the Residential Care Homes for the Elderly Persons in Hong Kong. 24th International System Safety Conference, Albuquerque, System Safety Society, pp. 627-635, 2006. 